FEATURE ARTICLE

\title{
Thoughts on a Pedagogy OF Complexity
}

\author{
DAVID BYRNE \\ Durham University (UK)
}

There is now a developed and extensive literature on the implications of the 'complexity frame of reference ${ }^{1}$ (Castellani \& Hafferty, 2009) for education in general and pedagogy in particular. This includes a wide range of interesting contributions which consider how complexity can inform, inter alia, research on educational systems (Cochran-Smith et al., 2014; Radford, 2008) and theories of learning (Mercer, 2011; Fromberg, 2010), as well as work dealing with specific pedagogical domains including physical education (Atencio et al., 2014, Tan et al. 2010), clinical education and in particular the learning of clinical teams (Noel et al., 2013; Bleakley, 2010; Gonnering, 2010), and learning in relation to systems engineering (Thompson et al., 2011, Foster et al., 2001). This material has contributed considerably to my thinking about the subject matter of this essay which is not the implications of complexity for pedagogy but rather how we might develop a pedagogy OF complexity and, more specifically, a pedagogy of what Morin (2008) has called 'general' (as opposed to 'restricted') complexity. In other words how should we teach the complexity frame of reference to students at all appropriate educational levels?

I have actually been doing this now for nearly twenty years through incorporating the complexity frame of reference to my teaching on Master's programmes in Social Research as well as for a time deploying it in teaching on a Doctoral programme in Business Administration (DBA). All of this teaching has been in relation to the delivery

${ }^{1}$ This term is better than the more commonly used 'complexity theory'. It indicates clearly that what we are deploying is a way of thinking about the world which is founded on an ontological understanding of much of that world as being composed of interacting and dynamic complex systems. 
of modules in 'Research Methods' which have the objective of preparing students to undertake their own original empirical research. For the Master's students this is in order to write an empirically-based dissertation as a foundation enabling those who pursue this path to continue to doctoral level research ${ }^{2}$, and for the DBA students, it was to write a shorter version than that of a Ph.D student for a doctoral thesis, but again the expectation was that this must be founded on original empirical research. The module in which I have 'taught Complexity' to a considerable extent is 'The Philosophy of Social Research' but I have also incorporated it into teaching on 'Quantitative Methods' and a foundational module covering 'Perspectives on Social Research' and colleagues, in particular my co-author Dr. Gill Callaghan (Byrne \& Callaghan, 2013), have drawn on the approach in modules on 'Qualitative Research' and others which have an 'applied and evaluative' focus. I have written two books Interpreting Quantitative Data (Byrne, 2002) and Applying Social Research (Byrne, 2012) which whilst not being, in a conventional sense, textbooks were nonetheless intended to contribute not only to how people thought about these two processes - interpreting quantitative data and applying social science - but to inform the teaching of complexity in terms of content. However, I devoted little attention to mode.

Like many and probably most people who start teaching new material at third and fourth levels, ${ }^{3}$ I really did not give much thought to how this should be taught but just started incorporating complexity thinking and complexity materials into what were, at least initially, conventionally delivered and assessed teaching programmes, albeit ones which involved a good deal of student led discussion and where the assessment was on the basis of module specific long essays and the actual dissertations / theses which were the 'craft of social research competency' final summary work by students. I have made assertions, most recently together with Callaghan in our book on Complexity theory and the social sciences: The state of the art (2013), about when the complexity frame of reference should be taught, arguing that it should be incorporated into teaching of students in the UK undertaking A levels, the two years of work prior to University entry equivalent to US Junior and Senior years in High School, and to students in the final years of secondary school education in general. Here I want to take the opportunity to think about how the complexity frame of reference should be taught at this and subsequent points through an education.

Let me return to the distinction between 'restricted complexity' and 'general complexity' because what interests me is how we can teach 'general complexity'. Morin puts it like this:

Restricted complexity made possible important advances in formalization, in the possibilities of modelling, which themselves favour inter-disciplinarity. But one still remains within the epistemology of classical science. When one searches for 'laws of

2 In the UK the degree of Ph.D. is awarded on the basis of the final thesis, usually of 80-100,000 words, and that alone. There are no course work requirements. Professional doctorates, the DBA, D.Ed., D.Psych, etc. do include a course work component.

${ }^{3}$ In Europe the term 'third level' is used to describe undergraduate programmes and fourth level to describe taught Masters programmes. 
complexity', one still attaches complexity as a kind of wagon behind the truth locomotive, that which produces laws. A hybrid was formed between the principles of traditional science and the advances towards is hereafter. Actually, one avoids the fundamental problem of complexity which is epistemological, cognitive, paradigmatic. To some extent, one recognizes complexity, but by decomplexifying it. ... In opposition to reduction, [generalized] complexity requires that one tries to comprehend the relations between the whole and the parts. The knowledge of the parts is not enough, the knowledge of the whole as a whole is not enough, if one ignores its parts; one is thus brought to make a come and go in loop to gather the knowledge of the whole and its parts. Thus, the principle of reduction is substituted by a principle that conceives the relation of the whole-part mutual implication. (Morin 2006, p. 6)

It is simplistic, but not necessarily wrong, to associate 'restricted complexity' with 'scientistic / conventional mathematical' approaches to complex systems. Actually Nicolis (1995) in his excellent textbook for Master's level students in the natural, and particularly physical, sciences does, as befits a colleague of Ilya Prigogine, have a sense of the nature of general complexity but that book stands as a demonstration of how we can present complexity in restricted terms. It is not simply that, as the title indicates, complexity is understood primarily in terms of systems which can be described by sets of non-linear equations, that is, in algebraic terms, albeit in an algebra which departs from the tyranny of the linear model. Nicolis is actually aware that complex systems are not easily handled even in those terms and that only local solutions may be possible - an acceptance of the impossibility of universal laws which generate causal explanations. The problem is that complexity is inserted into a traditional programme of nomothetic science rather than being separated from it.

Note here to say this is not to deny the validity of a programme for the construction of knowledge. It is rather to require a careful delimitation of the scale of application of such knowledge. Cilliers put it like this:

An argument will be presented against the view that a postmodern approach implies that "anything goes". Instead the suggestion will be that the approach is inherently sensitive to complexity, that it acknowledges the importance of selforganization whilst denying a conventional theory of representation. (1998, pp. 112-3)

Lyotard rejects an interpretation of science as representing the totality of all true knowledge. He argues for a narrative understanding of knowledges, portraying it as a plurality of smaller stories that function well within the particular contexts where they apply..... Local narratives only make sense in terms of their contrasts and differences to surrounding narratives. What we have is a selforganizing process in which meaning is generated through a dynamic process, and not through the passive reflection of an autonomous agent that can make “anything go". (1998, p. 114, 116)

To introduce Morin and Cilliers into the argument here is to take a philosophical turn. Most of my teaching of complexity has been 'philosophical' in form because it has been concerned with articulating an ontological position - complex realism after Reed and 
Harvey (1992) - which addresses the question fundamental for all empirical research: how can we claim to represent reality on the basis of the investigations into that reality which we have carried out in our research? At first sight this is an epistemological question but underlying the epistemology is an ontology. Before we can say anything about anything we have to understand the nature of the reality with which we are engaged.

The students I have taught on the Master's programmes in Social Research come from a variety of backgrounds across the social sciences and beyond. Those who have first degrees in Sociology or Anthropology generally have encountered some, however minimal, challenge to crude positivism in their undergraduate programme. This generally takes the form of some sort of justificatory account for the value of qualitative research processes and at the very least implies a rejection of any kind of hierarchy of knowledge generating processes with quantitative experimental research, whether bench or probabilistic, being regarded as some sort of 'gold standard'. The students who find the approach most challenging are not those with backgrounds in the general physical or biological sciences but those trained in the dominant UK tradition in psychology. The issue for them is not so much the idea of experimentation in terms of direct manipulation of small elements of reality but the absolute priority of knowledge generated by probabilistic experiments in the form of Randomized Controlled Trials (RCTs). Although RCTs have some value in establishing patterns of causation when we are dealing with simplicity where there is one cause for one effect, they are valueless if we are dealing with patterns of complex causation. This has particular significance for the development of an effective programme of evaluation, of establishing not just what works but what works in specific spatial / temporal contexts - what works when and where. More generally it was Znaniecki's (1928) identification of the inadequacies of probabilistic methods for identifying cause in contrast with the effectiveness of deterministic bench experiments which led him to formulate the approach of analytic induction, which is the precursor of methods of systematic comparison in the social sciences. Historians, anthropologists, sociologists, political scientists, and students from fields as opposed to disciplinary backgrounds - education, social work, business etc. are relatively comfortable with qualitative comparison as a fundamental process but not psychologists, unless they have field experience in clinical or educational contexts.

In trying to make sense of this I have turned to a kind of auto-ethnography, a life history of my own educational experiences. I started studying Sociology in 1966 in the first year the discipline was offered in my University. Sociology was not commonly taught in UK universities until the 1960s - a number of older UK departments including my own in Durham are celebrating their $50^{\text {th }}$ anniversary this year. Like many UK Sociology academics of my age (late 60s) I actually did not go to University to study Sociology. I went as a medical student - medicine in the UK is an undergraduate programme - with a secondary school pre University background in Physics, Chemistry, Biology and Maths (less usual for prospective medics than the first three) having studied Chemistry in particular to first year University level. My disillusion with the prospect of a career, even as a psychiatrist which had been my original career intention, was a 
product of the interaction of the realization that there was such a thing as social science which I could study, and a terror of having people die on me in my practice. When I raised this issue, the Dean of my medical school struck a deal with me saying that if I passed my first year exams then I could either continue in medicine or take up a degree in any other department which would have me. I actually liked much of the preclinical medical programme, in particular physiology. I passed my exams doing well in physiology and transferred to the new programme in Sociology and Social Administration. I wanted to do Sociology and Politics but that was not officially available. However, by taking Politics courses, particularly courses in Political Philosophy, I was able to do something very like that. Because I was good at Maths and could get high marks, I took all the statistics courses available including one which was conceptually advanced. Hubert Blalock's Social Statistics (1960) became a bible for me.

The point is that accidentally I somehow got a very broad education including elements in Physiology, Biology and Physical Chemistry which paid serious attention to systems and I was at least competent in Calculus and rather more than competent in basic Statistics. You never know what will come in handy! When I encountered complexity thirty years on in the 1990s, elements of all of this helped me to engage with it because I had a good of deal of the vocabulary from the 'hard sciences' and mathematics already to hand. I had avoided the over specialization which is the bane of particularly English ${ }^{4}$ secondary education and which tends to be exacerbated by the nature of the English three year undergraduate honours degree. The Social Policy element of my first and subsequent Master's degrees meant I had studied a lot of Economics and the political philosophy had given me a basic grounding in philosophical ideas. I had been 'broadened'.

It is precisely this broadening which seems essential to me as a basis for allowing students to engage sensibly with the implications of the complexity frame of reference for understanding the social world and the intersections of that social world with the natural world within which it is embedded. In the conventional terminology of academic administration we need to specify the pre-requisites for the sensible study of complexity in a way which facilitates this kind of broadening. This will, of course, lead us to question the way in which some of these subjects are conventionally taught. ${ }^{5}$ So competence in Mathematics and Statistics is essential but even more important than conventional competence in the use of mathematical and statistical methods is an understanding of what Mathematics is and an introduction to its wider terminology. The language of Topography is highly relevant to understanding the language of complexity. It is not that students need to be able to offer proofs in Topography but rather than they understand the terms deployed and the way they relate to complexity descriptions of the world. That is not an innocent statement. Behind it lies a very deliberate rejection of the Platonic assertion - see the myth of the cave - that reality is a transcendental domain of ideal forms. Here we take the Aristotelian position - reality is

4 The Scottish and Irish systems and many continental European systems are more broadly based.

${ }^{5}$ My seventeen year old daughter is doing English A levels now and I find that in Mathematics in particular she is being taught much in the way I was fifty years ago. 
its messy self. From that perspective mathematics is not a way in which we grasp the transcendental ideal but rather a very useful source of metaphors which are linked to each other through chains of formal proof.

We cannot ignore information technology here. Although the idea of emergence predates the development of digital computing by nearly a century, it is the development of that technology which provides us with tools which enable us to both data mine, explore enormous amounts of quantitative and now qualitative descriptions of what is and how it has come to be as it is, and simulate, construct artificial worlds which if calibrated on reality allow us to explore possibilities for the future development of reality. Simulation is not, for me, the gold standard method of exploring complexity, but calibrated simulation has its uses and to deal with both it and data mining, a basic understanding of what computers can do and how to do it using them is essential for the development of complexity thinking.

Likewise a grasp of biology with an emphasis on systems, which means both internal systems in the form of physiology and the whole environmental context of ecosystems, is very useful. Paleontology is particularly valuable because it provides a historical account of transformational changes of kind through its careful recording of punctuated equilibria. To say that is to introduce the significance of narrative. A great deal of what we do when we try to represent - re-presenting - presenting again, the social / natural world takes the form of narratives of becoming, enduring and ending. The great stories of macro historical sociology - the transition from Feudalism to Capitalism, the development of a transformed and globalized system of production and exchange, the collapse of the Soviet system - are narratives. Likewise micro social narratives, life stories, tell us about changes of kind - phase shifts - in everyday lives; the transition to and from a life of crime, social mobility up or down the occupational / class structure, the formation and dissolution of marriages. All of these are narratives which handled as social science incorporate causal accounts. This is what makes them scientific narratives as opposed to mere recountings of what has happened. Their essential characteristic is that they are stories of how things have come to be as they are. The causal focus enables us, we hope, to be able to say something about how things might be in the future because understanding of causes is fundamental for social interventions to achieve desired outcomes. This is the essence of retroductive method. Note very well that whilst most narratives are presented in words and written as texts, we must also recognize that a data series and even more a set of data series running through time are themselves narratives. Many of our statistical modelling techniques take the form of explorations of data series in an effort to generate causal accounts of becomings with becomings being the process by which systems come to be as they are at a point in time. Complexity deals with dynamic systems. Dynamism is change. We describe change through narratives and look for causes of change within those narratives.

So another set of prerequisites, building on the example of some discussion of paleontology in biology, comes from the humanities and social sciences. We can consider literature and history here, not so much for their specific content although that 
is always useful, as for the ways in which they demonstrate narrative development, and, from literary studies, offer us access to a range of kinds of narrative. ${ }^{6}$ Narratives bridge the disastrous quantitative / qualitative divide which has plagued not just the human sciences but science - understood here not in the conventional English sense of the word but as translation of wissenschaft / nauk - in general, that is to paraphrase the Gulbenkian Commission (1996) on the future of the social sciences, as secular organized knowledge about empirical reality with no privileging of either method of investigation or methodological framework.

If we look at existing pedagogical practice then in developing a programme of complexity pedagogy we have things to learn from critical thinking after Dewey and Glaser:

Critical thinking calls for a persistent effort to examine any belief or supposed form of knowledge in the light of the evidence that supports it and the further conclusions to which it tends. It also generally requires ability to recognize problems, to find workable means for meeting those problems, to gather and marshal pertinent information, to recognize unstated assumptions and values, to comprehend and use language with accuracy, clarity, and discrimination, to interpret data, to appraise evidence and evaluate arguments, to recognize the existence (or non-existence) of logical relationships between propositions, to draw warranted conclusions and generalizations, to put to test the conclusions and generalizations at which one arrives, to reconstruct one's patterns of beliefs on the basis of wider experience, and to render accurate judgments about specific things and qualities in everyday life. (Glaser 1941, p. 5)

In particular we have to think about 'reconstructing patterns of belief' with a special reference to the notion of 'the scientific method' as this is embodied in conventional teaching of physical and even biological science. We can also consider Freire's contrasting of banking education with dialogical learning and take account of the significance of power relationships in the formalization of knowledge and the institutional and pedagogical programmes surrounding that formalization. Since complexity predisposes us towards synthesis we can even add Foucault to the mix and recognize the power inherent in existing disciplinary and pedagogical discourses. Here we should return to the contrast between restricted and general complexity. Restricted complexity is 'acceptable'. It continues the forms of understanding which have dominated science since the Newtonian revolution. General complexity challenges those forms. We must be very careful not to fall into hippy dippy new ageist imprecision when we develop a pedagogy of complexity but we have to recognize a fundamental break in modes of understanding.

${ }^{6}$ The multi stranded narrative deploying characters who are not necessarily linked to each other - see for example Dos Passos (1937) - actually is a way of representing complexity and change. This kind of historical novel, including of course science fiction future histories Brunner (1969), is a way of using literary forms to deal with complexity. 
Any pedagogical programme has to be constructed around both content and form. For the complexity frame of reference specifying content is not difficult. I would suggest the following elements:

- The notion of emergence - what it means to say that the whole is greater than the sum of its parts.

- The nature of far from equilbric dynamic systems.

- Micro emergence and Macro emergence:

o Micro emergence - the emergence of phenomena from the interaction of agents.

o Macro emergence - the role of 'structure' and the significance of the interrelationships of systems with other systems.

- The philosophy of complexity - restricted and general complexity considered.

- The useful mathematical language of complexity:

o Non linearity

o The value of Topology.

- The significance of narrative.

- Exploring causality in complex systems - the role of comparison.

- The value and limitations of simulations.

- Modelling complexity - both necessary and impossible.

There will of course be variations on this by addition. For example in teaching social scientists I add in a good deal which addresses how we can evaluate interventions in complex social systems since this is a key issue in the application of social science. Any approach to ecological issues, including of course consideration of global warming, would pay a great deal more attention to modelling. However, the above is my shopping list.

Most of this can be taught to people preparing for University entry. UK A levels in the social sciences and humanities characteristically do not function simply to provide a foundational knowledge which will be added to subsequently, in the way that, say mathematics programmes function. Rather they consider fundamentals but at a foundational level. For me that works for complexity. Of course we could go a deal further as students acquire supporting knowledge in disciplines and fields to which the complexity frame of reference can be applied. So for example in teaching social scientists it is very useful to compare the complexity frame of reference with strong theoretical / methodological programmes, for example, Actor Network Theory.

So now let me turn to a much trickier issue - that of HOW we teach complexity. Here there are interesting developments in clinical training (e.g., Townsend et al., 2012) which draw explicitly on complexity thinking as a justification for developments. The general tenor of these is to support problem based learning approaches. The essence of problem based learning is that students work in groups in relation to a specific problem and develop ideas in interaction and in the context of the problem. Students are not expected to have all the knowledge required to resolve the problem already available to them but are instead required to locate knowledge which can help them in 
understanding and resolving the problem. Here it is useful to introduce the concept of wicked issues (Churchman, 1967) since the essence of the wicked issue is that it in issue in a complex system and the complexity frame of reference can be applied to understanding, and with a great deal of luck (!), resolving it.

Students cannot come to problem based learning innocent of all essential precursors. Teaching of clinical medicine in North American medical schools follows on a broad undergraduate education in biological and, to an increasing extent, social science. The pre-clinical element there has a lot of pre-requisites. Of course as complexity becomes more accepted as a general scientific frame of reference, then we might expect elements of its conceptual structure and language to become part of understanding in the foundational areas identified above as pre-requisites, but even before that develops there is a need for people who work collectively on problems to bring something with them before starting to do so.

I can see no difficulty in developing a problem based approach to undergraduate and Master's level education in complexity. This form of teaching is popular with students and works well in practice, for example in getting students to work as groups in conducting small scale research projects. It does however require a shift from the conventional in terms of assessment procedures. Typically students are assessed as individuals on their own performance. Indeed penalties are imposed if work is not the product of their own unique efforts. It is possible to evaluate collective work. I designed a second year undergraduate programme in research methods where the collective mark given for a collective group research project report counts for a quarter of total marks awarded with a further quarter awarded for the student's own reflection on both the experience of doing research and of working as a collective. This approach ticks two rather sensible boxes. It allows for reflective learning and it develops the transferable skill of group work. Students very much like doing this and report back that it plays well in job interviews where their prospective employers are well aware that group work is part of any professional / managerial career. The combination of collective assessment for the report and individual assessment for the personal reflection works well.

It has proved relatively easy to introduce this kind of approach for undergraduate teaching in social research methods and for the Master's training as a precursor to the Ph.D. It is not, however, how Ph.D.s have conventionally been done in the humanities and social sciences. In contrast the student taking a Ph.D. in the physical, life or biomedical sciences typically does work as part of a group but not in a problem based learning format. For problem based learning to work properly the group may well be presented with a problem but they have collectively to specify the nature of the problem and then identify the approaches which will be used to address it. The 'science' Ph.D. student usually has both the problem and the core of the approaches to it specified by their supervisor. Post docs working on team projects have more leeway to develop their own methods of attack but it is principal investigators who define the overall approach. Actually any ethnography of scientific research, for example the ethnographies conducted in the Actor Network style of work, always shows that things are somewhat 
looser in practice than that specification but it remains the norm as described certainly in research grant applications and often as constructed in reports of the research process. The Gulbenkian Commission (1996) called for the development of inter-disciplinary Ph.D.s, whilst recognizing the difficulties that doing one might pose for the development of a conventional academic career. However, it did not address the issue of how the Ph.D. should be done although it did emphasize broadening the focus of inquiry.

There are a lot of battles to be fought in the development of a sensible curriculum of complexity but there are important allies both within and outwith the academy. Business schools typically emphasize group work in case studies and projects precisely because they deal in the preparation of people for careers in real organizations where that is how things are done. Medical education has moved towards groups working through problem based learning because that is how clinical practice works in contemporary health systems. Precedents always help although in England the dominance of reactionary nostalgia among politicians concerned with education leads to a real hostility to innovations of this kind. However, this is an English disease and it not found to the same degree if at all in other parts of even the 'United' Kingdom. This can be done.

This article is intended to contribute to a debate about the pedagogy of complexity by chucking some ideas forward and stimulating a response. It draws on what is available in the literature and on my own teaching experiences. Others will have other ideas - good! However, if the complexity frame of reference changes the way we think, and for me it certainly does, then it should also change not only what we teach but also the way we teach. A change is as good as rest after all.

\section{References}

Bonnet, J. 2006. Stealing fire from the Gods: The complete guide to story for writers and filmmakers, 2nd ed. Studio City, CA: Michael Wiese.

Atencio, M., Yi, C.J., Clara, T.W.K., \& Miriam, L.C.Y. (2014). Using a complex and non-linear pedagogical approach to design practical primary physical education lessons. European Physical Education Review, 20(2), 244-263.

Blalock, H. (1960). Social statistics. New York: McGraw-Hill.

Bleakley, A. (2010). Blunting Occam's Razor: Aligning medical education with studies of complexity. Journal of Evaluation in Clinical Practice, 16(4), 849-855.

Brunner, J. (1969). Stand on Zanzibar. London: Panther.

Byrne, D. S. (2002). Interpreting quantitative data. London: Sage.

Byrne, D. S. (2011). Applying social science. Bristol: Policy Press.

Byrne, D. S. \& Callaghan, G. (2013). Complexity theory and the social sciences: The state of the art. London: Routledge.

Castellani, B., \& Hafferty, F. (2009). Sociology and complexity science. Berlin: Springer.

Churchman, W. (1967). Wicked problems. Management Science, 14(4), B141-B142.

Cilliers, P. (1998). Complexity and postmodernism. London: Routledge.

Cochran-Smith, M., Ell, F., Ludlow, L., Grudnoff, L., \& Aitken, G. (2014). The Challenge and promise of complexity theory for teacher education research. Teachers College Record, 116(5), 1-38.

Dos Passos, J. (1937). USA. New York: Harcourt Brace. 
Foster, J., Kay, J. Roe, P., Pudlowski, Z., \& Tai, D.W.S. (2001). Teaching complexity and systems thinking to engineers. $3^{\text {rd }}$ Asia-Pacific Forum on Engineering and Technology Education Proceedings: Monash Engineering Education Series 159-164.

Fromberg, D. P. (2010). How nonlinear systems inform meaning and early education' Nonlinear Dynamics, Psychology and Life Sciences, 14(1), 47-68.

Glaser, E. M. (1941). An experiment in the development of critical thinking. New York, NY: Teacher's College Press.

Gonnering, R. S. (2010). Complexity theory and "puzzling" competencies: Systems-based practice and practice-based learning explored. Journal of Surgical Education, 67(2), 122-4.

Gulbenkian Commission (Wallerstein Ch.) (1996). Open the social sciences. Stanford: Stanford University Press.

Mercer, S. (2011). Understanding leaner agency as a complex dynamic system. System, 39(4), 427-436.

Morin, E. (2006). Restricted complexity, general complexity. Retrieved from http://cogprints.org/5217/1/Morin.pdf

Nicolis, G. (1995). Introduction to nonlinear science. Cambridge: Cambridge University Press.

Noel, P. H., Lanham, H. J., Palmer, R. F., Leykum, L. K., \& Parchman, M. L. (2013). The importance of relational coordination and reciprocal learning for chronic illness care within primary care teams. Health Care Management Review, 38(1), 20-28.

Radford, M. (2008). Prediction, control and the challenge to complexity. Oxford Review of Education, 34(5), 505-520.

Reed, M. \& Harvey, D. L. (1992). The new science and the old: Complexity and realism in the social sciences. Journal for the Theory of Social Behaviour $\_22,356-79$.

Tan, C.W. K., Chow, J.Y., \& Davids, K. (2012). 'How does TGfU work?: Examining the relationship between learning design in TGfU and nonlinear pedagogy. Physical Education and Sport Pedagogy, 17(4), 331-348.

Thompson, A., Sattler, B., \& Turns, J. (2011). Understanding a studio environment: A complex systems approach to a community of practice. In Proceedings of the Frontiers in Education Conference (p. 10761081). New York, NY: IEEE.

Townsend, G.C., Kim, M., \& Sankey, D. (2011). Complexity theory as a new conceptual model for researching PBL in dental education. European Journal of Dental Education, 16(1), 43-51.

Znaniecki, F. (1928). Social research in criminology. Sociology and Social Research 12, 302-322.

\section{About the Author}

David Byrne is Professor of applied social sciences at Durham University. He has a background in applied social research including action research in community development and an interest in social inequality in post-industrial societies. Publications include Complexity Theory and the Social Sciences: An Introduction (1998), Interpreting Quantitative Data (2002), Applying Social Science (2011), and, with Gillian Callaghan, Complexity Theory and the Social Sciences: The State of the Art (2013).

(C) Copyright 2014. The author, David S. Byrne, assigns to the University of Alberta and other educational and non-profit institutions a non-exclusive license to use this document for personal use and in courses of instruction provided that the article is used in full and this copyright statement is reproduced. The authors also grant a non-exclusive license to the University of Alberta to publish this document in full on the World Wide Web, and for the document to be published on mirrors on the World Wide Web. Any other usage is prohibited without the express permission of the authors. 